\title{
Exploring the effects of high concentration of glucose on soil microbial community: An experimental study using the soil of North Bangalore
}

\author{
Anshuman Swain, \\ Second Year Undergraduate Student, Indian Institute of Science (IISc), Bangalore, India-560012
}

\begin{abstract}
Substrate Induced Respiration (SIR) is a standard method to study microbial biomass in soil. It is observed that the soil microbial $\mathrm{CO}_{2}$ respiration goes up with the glucose concentration till a certain concentration, and afterwards decreases and stabilizes. There are two possible mechanisms via which this can happen: increased osmotic pressure can kill off a group of microbial population or the Crabtree effect takes over the population. An experiment was designed using the SIR; to find the reason for the same and prove or disprove one of these hypothesises.
\end{abstract}

Key Words: Substrate Induced Respiration, Microbial Biomass, Crabtree Effect, Osmotic Pressure

\section{Introduction}

The technique of substrate induced respiration (SIR) has been designed to evaluate the degree of respiration in the soil due the employment of a substrate such as glucose, glutamic acid, mannitol and amino acids. The biological respiration reactions of the organisms present in the soil and their by-products, due to substrate addition, such as production of $\mathrm{CO}_{2}$ and/or consumption of $\mathrm{O}_{2}$, are used in this method as a measure of calculating the microbial activities in the soil. Anderson and Domsch came up with this process in 1978 to provide a swift valuation of the live microbial biomass in soils. The substrates that can be utilized are not limited to the aforesaid ones only; the choice of the substrate that is used should reflect the organisms that are in target and soil type that is being tested.

When this method of SIR is employed on a soil of North Bangalore, it was found that the total $\mathrm{CO}_{2}$ release due to respiration increased with the increase in glucose concentration but after it reached $0.4 \mathrm{~g} / 10 \mathrm{~g}$ of soil sample, it started to decrease fast and stabilized at a lower value. This means that the net respiration processes have decreased which can be a result of, a decrease in the total number of organisms (the rate of 
respiration remaining the same), a decrease in the rate of respiration (the number of organisms remaining the same) or a mixture of both the above reasons.

The first one will be due to high osmotic pressure (of glucose), which can cause the cells to die as they will not be able to withstand such a highly hypotonic solution. The second one will be due to Crabtree effect, in which many of the organisms generate the ATP using glycolysis only without going on to the Kreb's cycle and hence producing negligible $\mathrm{CO}_{2}$.

\section{Method}

Substrate induced respiration is used on the North Bangalore soil and the results of the carbon dioxide released versus the initial concentration of glucose is plotted and the

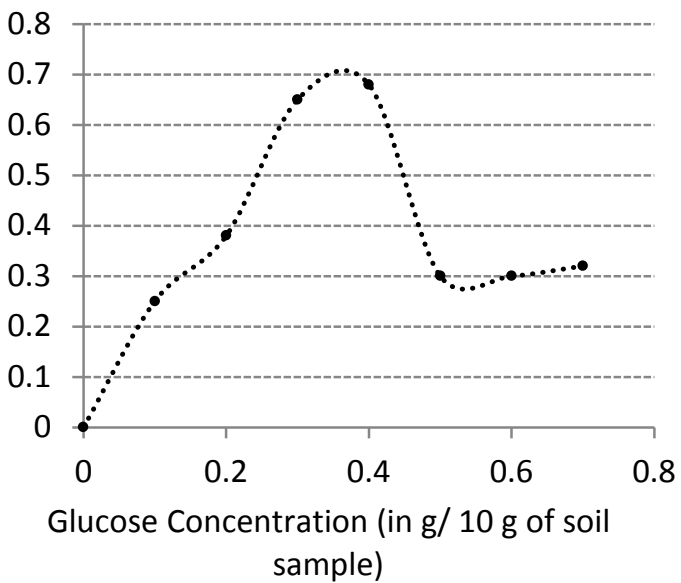

graph is shown in figure 1.

\section{Figure 1}

The reason for the decrease in the $\mathrm{CO}_{2}$ emission after the concentration of $0.4 \mathrm{~g} / 10 \mathrm{~g}$ of soil sample was reached, plausibly could be either the extreme osmotic pressure of the saturation of glucose or the Crabtree effect, To test which of the above two may be the reason of the decrease in $\mathrm{CO}_{2}$ emission, an experiment was designed through which it could be deduced whether or not in the higher concentration the organisms die or not.

The basic idea behind the experiment is to incubate the microbes in high glucose concentration and measure the $\mathrm{CO}_{2}$ emissions using SIR and then decrease the glucose concentration in the same sample \& incubate. Then it is compared with a control sample with the concentration, to which it was reduced later, which is also made to undergo SIR.

\section{Experiment}

The protocol was followed throughout the experiment involving the loamy soil collected from a site in Northern Bangalore (Karnataka, India). It had pH 8.34 and a water holding capacity of $4 \mathrm{~mL} / 10 \mathrm{~g}$ of soil. It was freshly collected and used, thus did not require any special incubation or other treatment. In SIR, the soil samples were measured at $10 \mathrm{gm}$ and put in a conical flask, then glucose of a certain concentration was added to it at $40 \%$ water holding capacity, and the mouth of the flask was corked and there was a tube through the cork connecting to another similar flask tilted horizontally at a higher elevation that containing $10 \mathrm{~mL} \mathrm{NaOH}$ solution of a 
certain concentration. The $\mathrm{CO}_{2}$ that will be released by the microbes in the flask

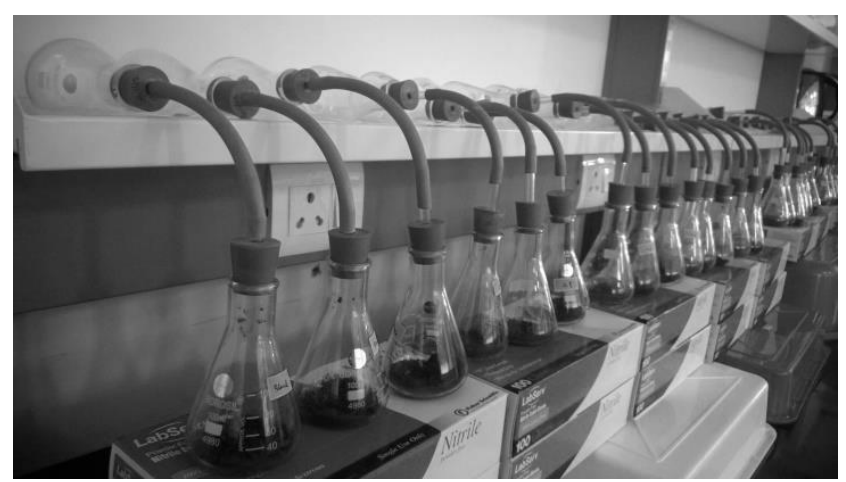

Figure 2. The Experimental Setup

will be absorbed by the $\mathrm{NaOH}$ solution in the other flask. Then the amount of $\mathrm{CO}_{2}$ released and that has been absorbed by the $\mathrm{NaOH}$ solution, is determined by titration against $\mathrm{HCl}$ of known concentration after addition $\mathrm{BaCl}_{2}$ or $\mathrm{Ba}\left(\mathrm{NO}_{3}\right)_{2}$ in order to precipitate the carbonate, and using phenolphthalein as the indicator, so as to determine the amount of $\mathrm{NaOH}$ left and hence the amount of $\mathrm{NaOH}$ used up in reaction against $\mathrm{CO}_{2}$.

Hourly $\mathrm{CO}_{2}$ emissions are checked using SIR for a $0.3 \mathrm{~g} / 10 \mathrm{~g}$ soil control concentration and a $0.6 \mathrm{~g} / 10 \mathrm{~g}$ test concentration for five hours and then after five hours, fresh $10 \mathrm{~g}$ of soil wetted with $1.6 \mathrm{~mL}$ distilled water is put in the test flasks containing the soil with higher glucose concentration. The experiment, as seen in figure 2 was repeated for 3 times and values were noted.

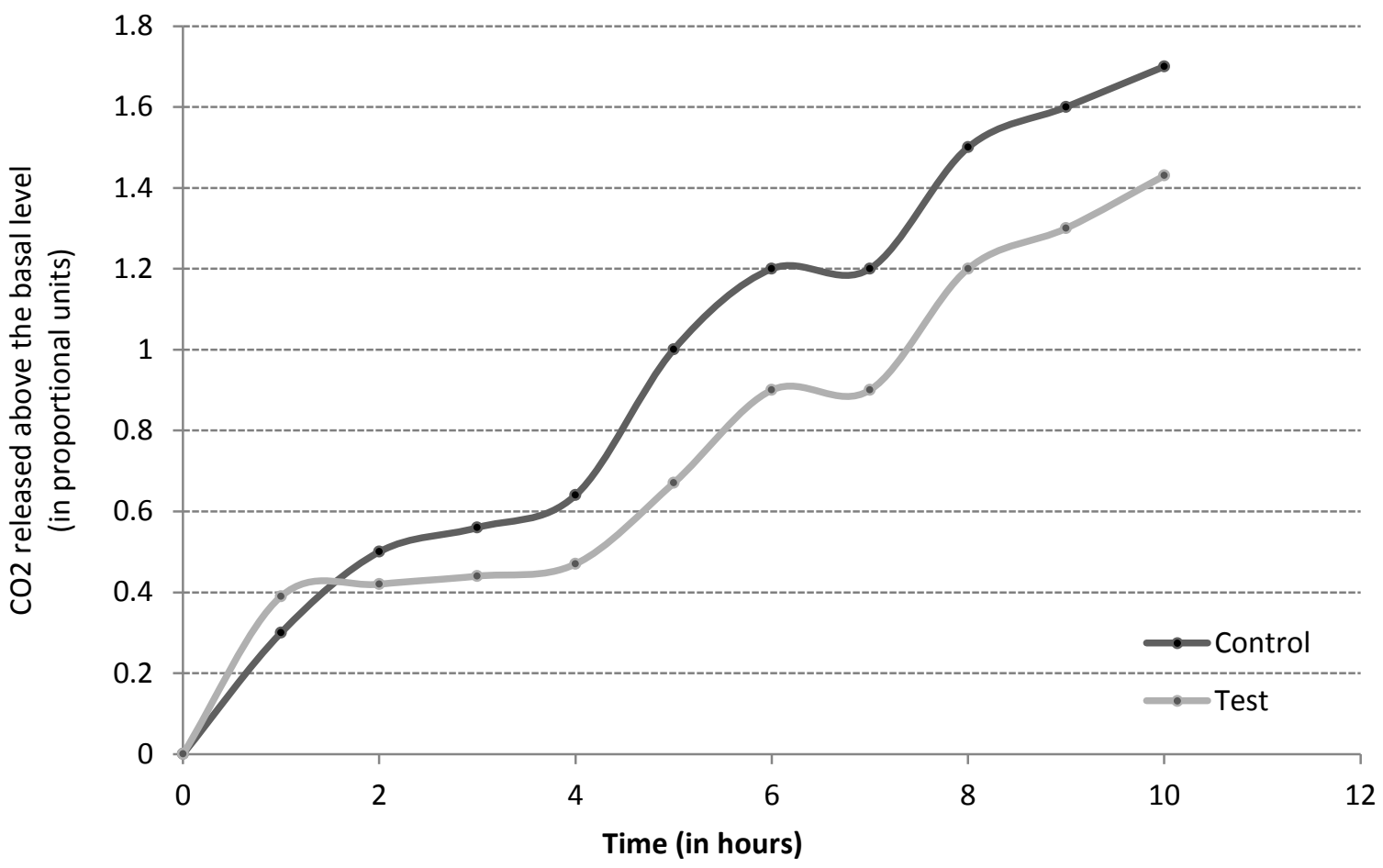

Figure 3. Comparative time varied graph 


\section{Results and Discussion}

All the values were statistically analysed using Matlab and the data was plotted as shown in figure 3 .

This graph actually disproves the osmotic pressure hypothesis and proves the Crabtree

effect. As seen in the beginning, the rate of $\mathrm{CO}_{2}$ emission is higher in case of higher glucose concentration (test sample) but the total amount soon becomes less than the control sample, this is what was observed in figure 1, and this continues till $5 \mathrm{hrs,} \mathrm{after}$ which both the concentrations are made equal, and had the increased concentration killed the microbes, there would have been lesser carbon dioxide emissions after $5 \mathrm{hrs}$ also, but as it is seen in the graph the amount of $\mathrm{CO}_{2}$ emitted after 5 hrs till the end of the experiment is same for both the cases, and hence the total number of organisms is nearly the same. The number of organisms in both the sample is same despite the fact that more soil was added, is that, after 5 hours, there would be the second generation microbes, which will be $2^{n+1}$ if the initial number is $n$ and moreover $n$ is quite large, hence $2^{n+1}$ is much greater than $n$. So when the new soil is added after 5 hours, the total number of microbes in the control sample is $2^{n+1}$ whereas that in the test sample is $2^{n+1}+n$, which is approximately equal to $2^{n+1}$.

So, from the results of figure 1, we can see that $57.14 \%$ of the total microbe population were affected by the Crabtree effect, as had there been no such effect; the total $\mathrm{CO}_{2}$ emission would have remained constant, even though the concentration would have increased and that would have signified the concentration of maximal glucose consumption and the decrease is due to Crabtree effect.

In addition, as the rate of $\mathrm{CO}_{2}$ emission is same for both cases after 5 hours, there is no observable decrease in the number of organisms, which would have been due to the deaths by high osmotic pressure.

\section{Conclusion}

From the designed experiment, it can be safely concluded that at high glucose concentrations, the microbes are affected by the Crabtree effect, in which they use the carbon nutrient source anaerobically to produce ATP and thus don't produce $\mathrm{CO}_{2}$. So, SIR cannot be satisfactorily be used for soils with high glucose dosage as it will give undermining results.

\section{Acknowledgements}

We are grateful to Dr Sumanta Bagchi for giving us an opportunity to work in his lab and also to $\mathrm{Mr}$ Manjunatha $\mathrm{H} \mathrm{C}$, for his great help in setting up the experiment and to other people in his lab for their sincere cooperation.

\section{References}

1. Anderson JPE and Domsch KH (1978), "A physiological method for the quantitative measurement of microbial 
biomass in soil", Soil Biol. Biochem. 10, pp.215- 221

2. Diaz-Ruizc R, Rigouleta M, and Devin A (2011), "The Warburg and Crabtree effects: On the origin of cancer cell energy metabolism and of yeast glucose repression", Biochimica et Biophysica Acta (BBA) - Bioenergetics, Volume 1807, Issue 6, June 2011, pp. 568-576

3. Cook FJ and Orchard VA (1984), "Relationship between microbial activity, soil water and substrate depletion", Proc. Aust. Soc. Soil Sci. Nat. Soils Conf., Brisbane, no. 371

4. Deken RHD (1966), "The Crabtree Effect: A Regulatory System in Yeast", J. gen. Microbiol. (1966), Iss. 44, pp. 149-156

5. Spading GP, Ord BG. and Vaughan D (1981), "Microbial biomass and activity in soils amended with glucose", Soil Biol. Biochem. 13, pp. 99- 104

6. Yamane I and Sato K (1964), "Decomposition of glucose and gas formation in flooded soil", Soil Sci. Plant Nutr. 10, pp. 35-41

7. Werf $\mathrm{H}$ van de, and Verstraete $\mathrm{W}$ (1987), "Estimation of active soil microbial biomass by mathematical analysis of respiration curves: calibration of the test procedure", Soil Biol Biochem 19: pp. 261-265

8. Ananyeva ND, Susyan EA, and Gavrilenko EG (2011), "Determination of the Soil Microbial Biomass Carbon Using the Method of Substrate-Induced
Respiration", Eurasian Soil Science, 2011, Vol. 44, No. 11, pp. 1215-1221.

9. Blagodatsky SA, Heinemeyer $\mathrm{O}$, and Richter J (2000), "Estimating the active and total soil microbial biomass by kinetic respiration analysis", Biol Fertil Soils, 2000,32: pp. 73-81

10. West AW and Sparling GP (1986), "Modifications to the substrate-induced respiration method to permit measurement of microbial biomass in soils of differing water contents", Journal of Microbiological Methods 5, 1986, pp. $177-189$

11. Anderson JPE, and Domsch H (1973), "Quantification of bacterial and fungal contributions to soil respiration", Arch. Mikrobiol. 93, pp. 113-127

12. Werf H van de, Verstraete W (1987), "Estimation of active soil microbial biomass by mathematical analysis of respiration curves: development and verification of model", Soil Biol Biochem 19:pp. 253-260

13. Vance ED, Brookes PC, Jenkinson DS (1987), "An extraction method for measuring soil microbial biomass C", Soil Biol Biochem 19:pp. 703-707

14. Stotzky G, Norman AG (1961), "Factors limiting microbial activities in soil. I. The level of substrate, nitrogen and phosphorus", Arch Mikrobiol 40:pp. 341-369

15. Stenström J, Stenberg B, Johansson M (1998), "Kinetics of substrate-induced respiration (SIR): theory", Ambio 27:pp. 35-39 
16. Smith JL, McNeal BL, Cheng HH (1985), "Estimation of soil microbial biomass: an analysis of the respiratory response of soils", Soil Biol Biochem 17 :pp. 11-16

17. Colores GM, Schmidt SK, Fisk MC (1996), "Estimating the biomass of microbial functional groups using rates of growth-related soil respiration", Soil Biol Biochem 28: pp. 1569-1577 